\title{
LA VIVACIDAD DEL PENSAR. BREVE PRESENTACIÓN DE TRES TEXTOS INTRODUCTORIOS DE MARC RICHIR
}

\author{
Pablo Posada Varela \\ Bergische Universität Wuppertal, Alemania - \\ Université Paris-IV-Sorbonne, Francia \\ pabloposadavarela@gmail.com
}

Los tres textos que traducimos en este número de Investigaciones Fenomenológicas tienen la virtud de ser excelentes presentaciones de elementos nodales de la fenomenología de Richir (que, evidentemente, tiene ramificaciones que no trasparecen a estos textos).

El primero es el último de ellos en el tiempo: "El sentido de la fenomenología". Es el texto de un filósofo que, andado el tiempo, maduros los posos y dibujados los sedimentos, vuelve la vista atrás y hace cierto balance sobre el sentido de su propuesta fenomenológica (que bautiza "fenomenología no estándar" dando por buena una sugerencia de su amigo Jean Toussaint Desanti). El respeto de Richir a Husserl, fundador de la fenomenología, es evidente. Apoyándose en un texto de Husserl, introduce Richir con maestría algunos de sus conceptos fundamentales (afectividad, protoontología, esquematismo, desajuste como nada o nonada de espacio y de tiempo).

El segundo de los textos, "Phantasia, imaginación e imagen", es testimonio del giro que conoce la fenomenología richiriana en el año 2000, a partir de Phénoménologie en esquisses. Se trata, efectivamente, del descubrimiento, por parte de Richir, de los tesoros durmientes de la fenomenología husserliana de la phantasia. Tesoros que, desde 1980, fecha de publicación del husserlianum XXIII, dormitaban en sus páginas.

El tercero de los textos, "Leiblichkeit y Phantasia", parte ya del siguiente buceo en Hua XXIII que acomete Richir en busca de nuevos elementos ausentes en Phénoménologie en Esquisses. Esos nuevos pecios rescatados de los 
manuscritos de Husserl catalizarán la ampliación de ese redescubrimiento de la fenomenología husserliana de la phantasia al territorio de la $\operatorname{afectividad}^{1}$ (y de la psicopatología como uno de sus reveladores fundamentales ${ }^{2}$ ). Ese esfuerzo cristaliza en la gran obra que es Phantasia, Imagination, Affectivité (2004). En el texto Leiblichkeit y Phantasia es interesante advertir una suerte de vuelta, con el afinado instrumental husserliano de la fenomenología de la phantasia, a la profunda lectura de los tres tomos de Husserl sobre intersubjetividad que ya hiciera Richir, en sus Meditations Phénoménologiques (1992), desprovisto entonces de los pecios rescatados de Hua XXIII. Como señalábamos más arriba, la lectura prolongada de Hua XXIII se hace en dos etapas, que corresponden grosso modo a Phénoménologie en esquisses (2000) y Phantasia, Imagination, Affectivité (2004). Este segundo raqueo (ien el mejor de los sentidos!) se salda con nuevos tesoros como la phantasia perceptiva (texto n¹8 de Hua XXIII) o la cuestión del Phantomleib (texto nº16 de Hua XXIII) y una profundización de la cuestión del Fiktum $^{3}$ y de la complejísima estructura de la aprehensión de imaginación en general (no bien entra en juego la cuestión de la afectividad), en su diferencia con la "aprehensión" de phantasia. A la luz de estos conceptos y de las profundas enseñanzas husserlianas sobre la phantasia en general ${ }^{4}$ se

\footnotetext{
${ }^{1}$ De ahí el interés de Richir por las investigaciones de Antonio Zirión o de algunos de sus alumnos como, por ejemplo, Ignacio Quepons.

${ }^{2}$ Cfr. los interesantes trabajos que sobre este aspecto de la fenomenología de Richir ha emprendido Luís Antonio Umbelino. Por ejemplo, pero no sólo, este artículo en un número de la revista Arbor editado por Agustín Serrano de Haro: Luís Antonio Umbelino, "Sobre a Stimmung. Biranismo e Fenomenologia". Pdf, Arbor. Ciencia, Pensamiento y Cultura, vol. CLXXXV, 736 (2009).

${ }^{3}$ Que, precisamente, no tiene, en Husserl, carácter de suyo como sí lo tiene en Zubiri. Esto abre a infinitas y muy fructíferas discusiones. Creo que cabe una interesantísima discusión entre Richir y Zubiri en punto al estatuto fenomenológico de la realidad, que Richir aborda de la mano del concepto husserliano de phantasia "perceptiva" en las últimas páginas de Phantasia, Imagination, Affectivité (2004) y más detenidamente en los Fragments phénoménologiques sur le temps et l'espace (2006). Confrontación mucho más interesante y fructífera que la que insinúa Tengelyi entre Richir y Marion en Neue Phänomenologie in Frankreich, Suhrkamp, 2011. Entre otras cosas porque hay cierta diferencia en seriedad y profundidad filosófica y fenomenológica entre el por muchas razones admirable Xavier Zubiri y el flamante nuevo miembro de la Académie Française Jean-Luc Marion. Diferencia que no corre precisamente a favor del último. Sobre la mayor oportunidad de una confrontación Richir-Zubiri y la falsamente planteada confrontación Richir-Marion pueden consultarse con provecho los desarrollos contenidos en la parte IV. (pp. 28-33) de "Concrétudes en concrescences" (art. cit.).

${ }^{4}$ Al decir de Richir, ningún filósofo ha ido nunca tan lejos como Husserl en estas cuestiones tan difíciles, tan móviles y recónditas. Y no sólo en el terreno de la phantasia, también en el de la Imaginación y en el de la conciencia de imagen. La extraordinaria precisión de los textos de Hua XXIII va bastante más allá y más al fondo que muchos sesudos o coloridos tratados contemporáneos sobre el fenómeno de la "imagen", tratados tan espectacularmente documentados e ilustrados como ajenos a las matrices esenciales del problema. A dar con las articulaciones fundamentales del fenómeno de la realidad virtual (por caso) no ayuda esencialmente el estar uno puesto al día sobre la última de las técnicas de generación de realidades virtuales o sobre la vanguardia del cine de ciencia ficción. Sin que lo último deje de tener su interés (que lo tiene) sostengo que los instrumentos de su análisis residen en la fenomenología husserliana de las experiencias de representificación y eso no requiere de ningún viaje espectacular a las últimas tecnologías. Dicho de otro modo: lo nodal ya estaba celado en la experiencia consistente en mirar una simple fotografía o un cuadro, experiencia tan común como insospechadamente intrincada. Hasta
} 
recorren los territorios de Hua XIII-XIV-XV que ya habían hollado las Méditations Phénoménologiques en 1992.

que no entendamos a fondo qué pasa ahí no podremos emprender con provecho y precisión el análisis de los elementos novedosos que configuran nuestro presente así como sus nuevos tipos de experiencia $y$, acaso, nuevas ontologías regionales como, con mucho tino, ha sugerido en ocasiones el profesor César Moreno Márquez. 